\title{
Demonstração temporal de mortes decorrentes de agressões físicas no Estado do
}

\author{
Amazonas \\ Temporal demonstration of deaths resulting from physical attacks in the State of Amazonas \\ Demonstración temporal de muertes por agresiones físicas en el Estado de Amazonas
}

Recebido: 09/02/2021 | Revisado: 12/02/2021 | Aceito: 15/02/2021 | Publicado: 22/02/2021

Rúbia Silene Alegre Ferreira

ORCID: https://orcid.org/0000-0001-6786-9948

Universidade Católica de Brasília, Brasil

E-mail: rubia.alegre.ferreira@gmail.com

Quézia Correa de Oliveira Sampaio

ORCID: https://orcid.org/0000-0002-9248-334X

Universidade Federal do Amazonas, Brasil

E-mail: queziapretty@hotmail.com

Aldo Raphael Mota de Oliveira

ORCID: https://orcid.org/0000-0002-4276-9040

Centro Universitário do Norte, Brasil

E-mail: aldo.oliveira@uninorte.com.br

Geiza Elem Souza de Matos

ORCID: https://orcid.org/0000-0001-7222-2372

Centro Universitário do Norte, Brasil

E-mail: geiza.matos@gmail.com

James Barros Monteiro

ORCID: https://orcid.org/ 0000-0003-3978-5151

Centro Universitário do Norte, Brasil

E-mail: jamesmonteiro74@gmail.com

\begin{abstract}
Resumo
Faz-se a demonstração das agressões que resultam em mortes no estado do Amazonas em série histórica, compreendendo o período de 23 anos. Nesta linha de tempo, o foco considera as mortes por faixa etária, escolaridade, estado civil e por local de ocorrência. Os dados são oriundos do Sistema de Informações sobre Mortalidade - SIM do DATASUS/MS, com início em 1996, finalizando em 2019. Os resultados sinalizam que dos sete grupos estudados, tanto para homens quanto para mulheres, três destes são os que se destacam com os maiores eventos: 15 a 19; 20 a 29 e 30 a 39 anos. À medida que a escolaridade se eleva, as mortes decorrentes de agressão são menores e o estado civil embora apresente-se com maiores casos para os solteiros, não é garantia de isenção nestas fatalidades. O local das mortes aponta que boa parte destas se dá em vias públicas e em hospitais para as mulheres, com relativa representatividade de óbitos em domicílio. Para os homens, a maioria absoluta se manifesta em hospital, com eventos muito próximos em via pública e nos domicílios, porém em escalas menores. Assim, a violência ainda é uma das mazelas mais graves que acompanham humanidade, mas que carece de ações de enfrentamento e tratativa.
\end{abstract}

Palavras-chave: Mortes; Agressões; Amazonas; Série histórica.

\begin{abstract}
A demonstration of the aggressions that result in deaths in the state of Amazonas in historical series, covering the period of 23 years. In this timeline, the focus considers deaths by age group, education, marital status and place of occurrence. The data come from the DATASUS / MS Mortality Information System - SIM, starting in 1996, ending in 2019. The results indicate that of the seven groups studied, both for men and women, three of these are the ones that stand out with the biggest events: 15 to 19; 20 to 29 and 30 to 39 years. As schooling increases, deaths from aggression are lower and marital status, although it presents more cases for singles, is no guarantee of exemption from these fatalities. The location of the deaths points out that a large part of these occur on public roads and in hospitals for women, with a relative representation of deaths at home. For men, the absolute majority is manifested in a hospital, with events very close on public roads and at home, but on smaller scales. Thus, violence is still one of the most serious ailments that accompany humanity, but it lacks actions to confront and deal with it.
\end{abstract}

Keyword: Deaths; Aggressions; Amazonas; Historic serie.

\section{Resumen}

Una demostración de las agresiones que provocan muertes en el estado de Amazonas en una serie histórica, que abarca el período de 23 años. En esta línea de tiempo, el enfoque considera las muertes por grupo de edad, educación, 
estado civil y lugar de ocurrencia. Los datos provienen del Sistema de Información de Mortalidad DATASUS / EM SIM, desde 1996 hasta 2019. Los resultados indican que de los siete grupos estudiados, tanto de hombres como de mujeres, tres de estos son los que destacan con mayor eventos: 15 a 19; 20 a 29 y 30 a 39 años. A medida que aumenta la escolaridad, las muertes por agresión son menores y el estado civil, aunque presenta más casos para los solteros, no garantiza la exención de estas muertes. La ubicación de las muertes señala que gran parte de estas ocurren en la vía pública y en hospitales para mujeres, con una representación relativa de muertes en el hogar. Para los hombres, la mayoría absoluta se manifiesta en un hospital, con eventos muy cercanos en la vía pública y en el hogar, pero a escalas menores. Así, la violencia sigue siendo una de las dolencias más graves que acompañan a la humanidad, pero carece de acciones para afrontarla y afrontarla.

Palabras clave: Fallecidos; Agresiones; Amazonas; Serie histórica.

\section{Introdução}

A redução da mortalidade é algo que se pode ter por certo, como resultado de diversos fatores que atuaram conjuntamente no sentido de tornar esses eventos em número menor, como por exemplo o avanço da medicina, das descobertas científicas, dos avanços na tecnologia, das formulações e reformulações legislativas, dentre outros fatores.

A medicina progrediu de forma tão considerável que possibilitou por meio dos medicamentos, dos tratamentos e de diversas ferramentas, a redução de patologias que por anos dizimaram populações. Um destes mecanismos é a imunização, que possibilita a partir da gestação e dos primeiros anos de vida do bebê, anos a mais de vida. De igual modo, as descobertas científicas, contribuíram substancialmente neste processo.

As formulações e reformulações legislativas, ampliam e garantem modos laborais e coberturas que de modo efetivo agregam condições de trabalho em formas mais humanas, com menores riscos e exposições. Não obstante, em ponto contraditório a estes eventos, a mortalidade decorrente das causas externas é um agravante que carece de um olhar mais detido, pelas diversas áreas do conhecimento e do Estado.

Como fenômeno sócio-histórico, a violência acompanha toda a experiência da humanidade. Sua presença está registrada em vários documentos da Antiguidade e é lembrada no mito de origem contido na narrativa bíblica em forma de disputa fratricida. Os ressentimentos de Caim contra seus pais e a morte de Abel, seu irmão, pensada e perpetrada por ele, evidenciam a convivência da sociedade humana com perenes disputas de poder, com ódios e com a vontade de aniquilar uns aos outros. Essa vontade de aniquilamento, no decurso da história e das culturas, se manifesta de várias formas como: desprezo e menosprezo pelo outro, discriminações, crueldades, autoritarismo, lutas fratricidas, guerras, terrorismos e processos de autodestruição, (Minayo 2006).

Estamos habituados a encarar a violência como um ato enlouquecido, pelo prisma de uma exceção, ou seja - como transgressão de regras, normas e leis já aceitas por uma comunidade. Violência, em nosso imaginário, está permanentemente associada à marginalidade, aos atos físicos de abuso (assalto, assassinato, etc), ou à ruptura de normas e leis que são respeitadas por uma determinada comunidade, na fala de Vilhena e Maia (2002).

Em Bonamigo (2008), verifica-se que a análise do sentido etimológico coloca em relevo que é a percepção do limite que vai caracterizar um ato como violento e essa percepção varia histórica e culturalmente. Portanto, o termo não pode ser definido independentemente de critérios e de pontos de vista, os quais podem ser institucionais, jurídicos, sociais e até pessoais. Não se pode deixar de fora o que é eminentemente normativo e não existe uma abordagem objetiva que consiga pôr entre parênteses todas as normas. Querer engessar a expressão em uma definição fixa e simples significa reduzi-la e deixar de compreender as singularidades que caracterizam diferentes povos, as transformações e especificidades históricas. Há, portanto, possibilidade da existência de inúmeras formas de violência relacionadas às inúmeras situações e espécies de normas estabelecidas.

Segundo Dias (2000), se examinarmos as raízes da agressividade, temos que levar em conta: 1. a raiz instintual da destrutividade, que é inerente ao impulso amoroso primitivo; 2. a motilidade (erotismo muscular) como manifestação do estar- 
vivo; 3. a reação à falha ambiental, que interrompe a linha do ser e traumatiza; 4. num momento posterior, dentro ainda dos chamados estágios iniciais, a destrutividade no anger, que leva à criação da externalidade e ao uso do objeto como uma entidade por seu próprio direito.

Um dos problemas que mais se debatem hoje em todos os círculos, sociais, políticos, científicos, populares, acadêmicos, é o da violência. Mesmo porque, ele se atrela ao da criminalidade, embora não lhe corresponda exatamente. A esses debates não pode se furtar a Psicologia Jurídica, obviamente. As manifestações da violência podem ter suas implicações jurídicas, não só criminais, mas também em sede de justiça da família e da infância e juventude, já que a violência encontra um de seus mais importantes berços no próprio seio familiar. $\mathrm{O}$ assunto é por demais vasto. A violência, em si, poderia ser, como já tem sido, tema de eventos científicos, (Sá, 1999).

Em várias das representações sociais da violência contemporânea, sejam da mídia, sejam do senso comum intelectual, encontramos implícita uma denúncia do conflito, como se esse pudesse ser substituído por uma competição cavalheiresca regulada. Se, por um lado, as acusações de violência, feitas a um Outro, reclamam tolerância às diferenças, por outro, parecem pautar conflitos identitários, de raça, gênero, religião ou nação que podem também incorporar efeitos de violência, Missi (2019).

É apenas a passagem do tempo e a experiência do viver que tornam possível a um indivíduo, já rapaz ou moça, aceitar gradativamente a responsabilidade por tudo o que ocorre no mundo de sua fantasia pessoal, além de toda a tensão que está associada à identidade de gênero e à escolha sexual do objeto. Quando o começo foi bom e as bases são sólidas e verdadeiras, porque pessoais, ainda assim haverá turbulência mas, se o ambiente continua a fornecer as condições favoráveis, as chances de a espontaneidade básica sobreviver e o indivíduo continuar a amadurecer são grandes, (Dias 2000).

Para Maia e Vilhena (2002), ao contrário dos animais, o homem só é, muito parcialmente, um ser biológico. Sua existência propriamente humana e social só se realiza através de sua imersão no simbólico, isto é num conjunto de códigos que permite que se comunique e se relacione com outros homens e com o universo que o circunda - a cultura é assim, a própria condição de possibilidade do humano.

Assim como é preciso reconhecer que o significado de violência vem se ampliando junto com o processo civilizatório e que o conceito de violência está ainda sendo produzido em sua polissemia, é necessário não subestimarmos, no conceito, aquilo que provoca maior reação moral e atinge de forma mais aguda a sensibilidade moral de uma sociedade e de uma época. Nesse sentido, o homicídio e as diversas formas de crueldade impingidas a um indivíduo ou grupo vem a constituir, na modernidade que cultiva o valor da vida e da dignidade do indivíduo, a violência mais evidente e inaceitável tipificada nos crimes mais puníveis. Entretanto, também aqui há paradoxos e contextualizações de cada caso e é preciso estar atento à produção de sentido local ou contingente, (Missi, 2019).

Para Barros e Silva (2006), a conduta agressiva parece se manifestar por uma série de razões que podem coexistir ou, até mesmo, serem complementares. Algumas vezes, esse processo se torna complexo e exige que compreendamos a participação de múltiplos fatores na formação da agressividade.

Neste trabalho faz-se a demonstração temporal das agressões que resultam em mortes no estado do Amazonas, compreendendo o período de 23 anos. Nesta linha de tempo, o foco considera as mortes por faixa etária, escolaridade, estado civil e por local de ocorrência. Os dados são oriundos do Sistema de Informações sobre Mortalidade - SIM do DATASUS/MS, com início em 1996, finalizando em 2019.

A estrutura está assim definida, além desta introdução bem como desta revisão bibliográfica a respeito da questão subjetiva das ações violentas. Na metodologia, apresenta-se a forma utilizada para dar conta do que se propôs na investigação. Na discussão dos resultados, se exibe os achados da pesquisa e por fim, tece as considerações finais. 


\section{Metodologia}

A pesquisa científica é fundamental enquanto meio de se garantir a construção do saber no interior das universidades, para que estas possam cumprir com o seu papel social de determinantes do bem-estar e soberania de um povo. E segundo Naves (1998), apresenta algumas peculiaridades, tais como:

1. Centra-se em torno de um problema: a razão de ser de uma pesquisa é a de estar encaixada, centrada em um problema e não necessariamente, resolver problemas ou ter uma aplicação prática imediata - Envolve trabalho criativo: todas as fases de uma pesquisa envolvem trabalho criativo. Para ser criativo implica em ter "curiosidade científica";

2. Visa descobrir generalizações: toda pesquisa em ciências naturais, como a nutrição, tem a propriedade de generalização (indução), isto é, transferir a informação obtida a partir de uma amostra, para toda a população de origem. Deve-se tomar muito cuidado com as generalizações. Uma pesquisa permite fazer inferências somente quando apresenta dados de boa qualidade (confiáveis), analisados de forma cientificamente apropriada;

3. Visa "dominar" um fenômeno: a pesquisa procura "escancarar" um fenômeno, uma situação em particular, através da geração de novos conhecimentos e novos problemas, levando a um maior entendimento do fenômeno na sua generalidade, visando generalizações

Enquanto abordagem esta pesquisa é de natureza qualitativa e quantitativa, que segundo Mezzaroba e Monteiro (2009) a primeira é uma propriedade de ideias, coisas e pessoas que permitem que sejam diferenciadas entre si de acordo com suas naturezas. A pesquisa qualitativa não vai medir seus dados, mas, antes, procurar identificar suas naturezas. O objeto da pesquisa vai ser tratado de forma radicalmente diferente da modalidade anterior de investigação. No caso da segunda, faz a descrição rigorosa das informações obtidas é condição vital para uma pesquisa que se pretenda quantitativa. Para Günther (2006), o fato de qualificar experimento e avaliação com o adjetivo "qualitativo" reforça a constatação de que estes procedimentos, além da interpretação tradicional da pesquisa quantitativa, podem incluir uma abordagem qualitativa.

Os dados são oriundos do Sistema de Informações sobre Mortalidade - SIM do DATASUS/MS, com início em 1996, finalizando em 2019 e disponibilizados por meio de série histórica, que podem contribuir no sentido de mostrar "como foi" no decorrer da linha do tempo e possibilitar "pistas" de como proceder para atuar na problemática apontada.

\section{Resultados e Discussão}

\subsection{Mortes por agressões - faixa etária}

Antes de detalharmos os dados das mortes por agressão no estado do Amazonas nesta série histórica, interessa mostrar como se dá este fato por faixa etária para os gêneros. A idéia é a de poder perceber em qual idade essa consequência se intensifica. Por meio dos dados nota-se que a idade mais aguçada no quesito agressões, corresponde ao grupo de 20 a 29 anos. Uma fase de vigor na juventude. E pelo desenrolar da série histórica desta faixa etária, é uma tendência de crescimento que se mostra com elevação de picos em dados períodos, porém mantendo-se em uma trajetória de evolução. Na Figura 1 faz-se a demonstração de mortes decorrentes de agressão para os homens do Amazonas por faixa etária. 
Research, Society and Development, v. 10, n. 2, e44310212782, 2021

(CC BY 4.0) | ISSN 2525-3409 | DOI: htttp://dx.doi.org/10.33448/rsd-v10i2.12782

Figura 1: Mortes por agressão física de homens no Amazonas por faixa etária.

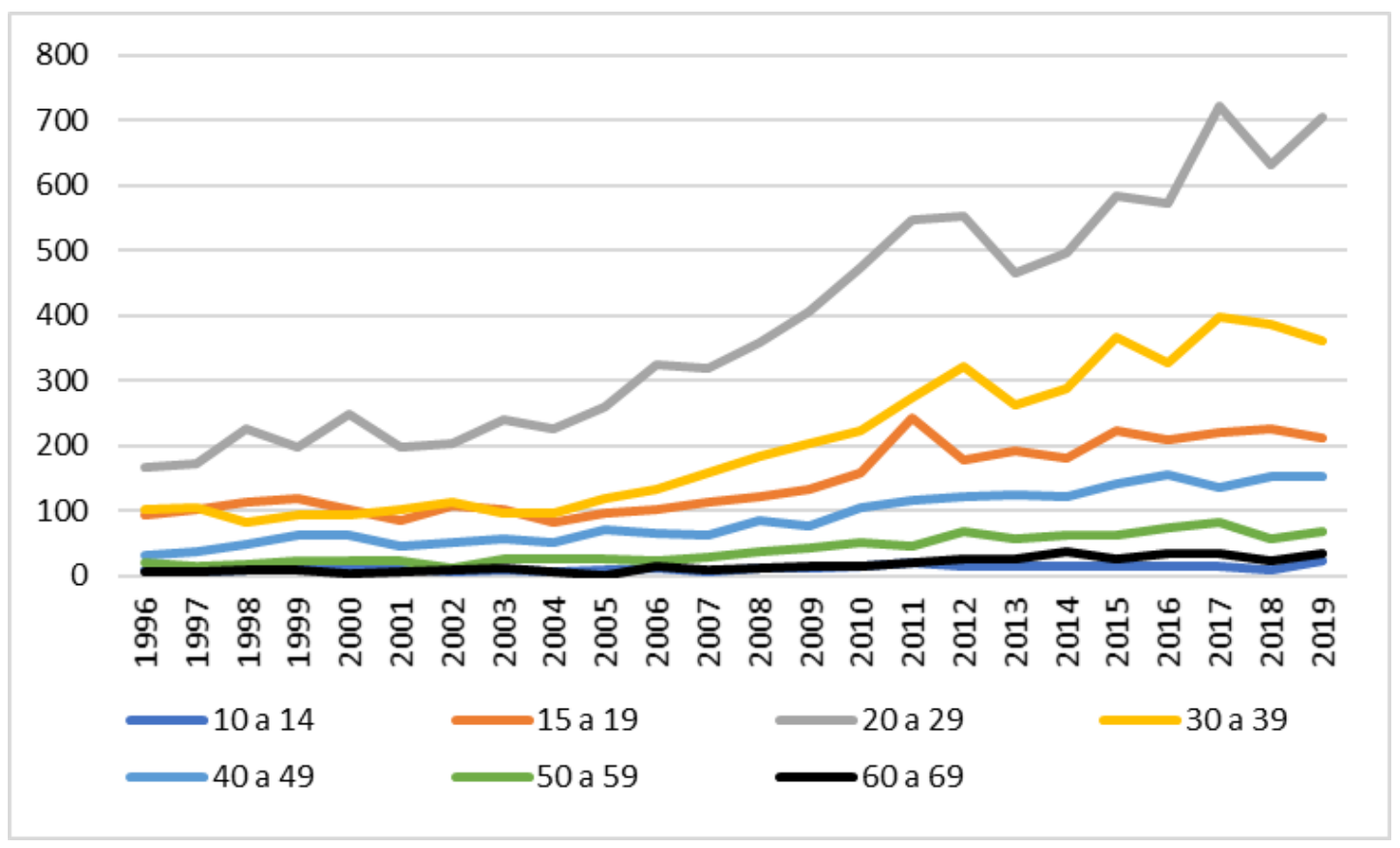

Fonte: MS/SVS/CGIAE - Sistema de Informações sobre Mortalidade - SIM.

O segundo grupo etário de mortes por agressão diz respeito aos pertencentes aos de 30 a 39 anos de idade. Compreende uma fase adulta. Em seguida, a terceira posição é ocupada por homens de 15 a 19 anos, que de modo semelhante ao primeiro grupo visto, apresenta trajetória de progresso neste sentido. Os homens do grupo de 40 a 49 anos são aqueles que em nível escalar situam-se entre as mortes que não ultrapassam o limite de 100 óbitos na série percebida.

As idades mais avançadas (nesta série), mostram-se em menores participações na categoria investigada (50 a 59 e de 60 a 69 anos). Na Figura 2, verifica-se esta questão considerando-se as mortes por agressões relacionadas às mulheres do Amazonas no mesmo recorte temporal. 
Figura 2: Mortes por agressão físicas de mulheres no Amazonas por faixa etária.

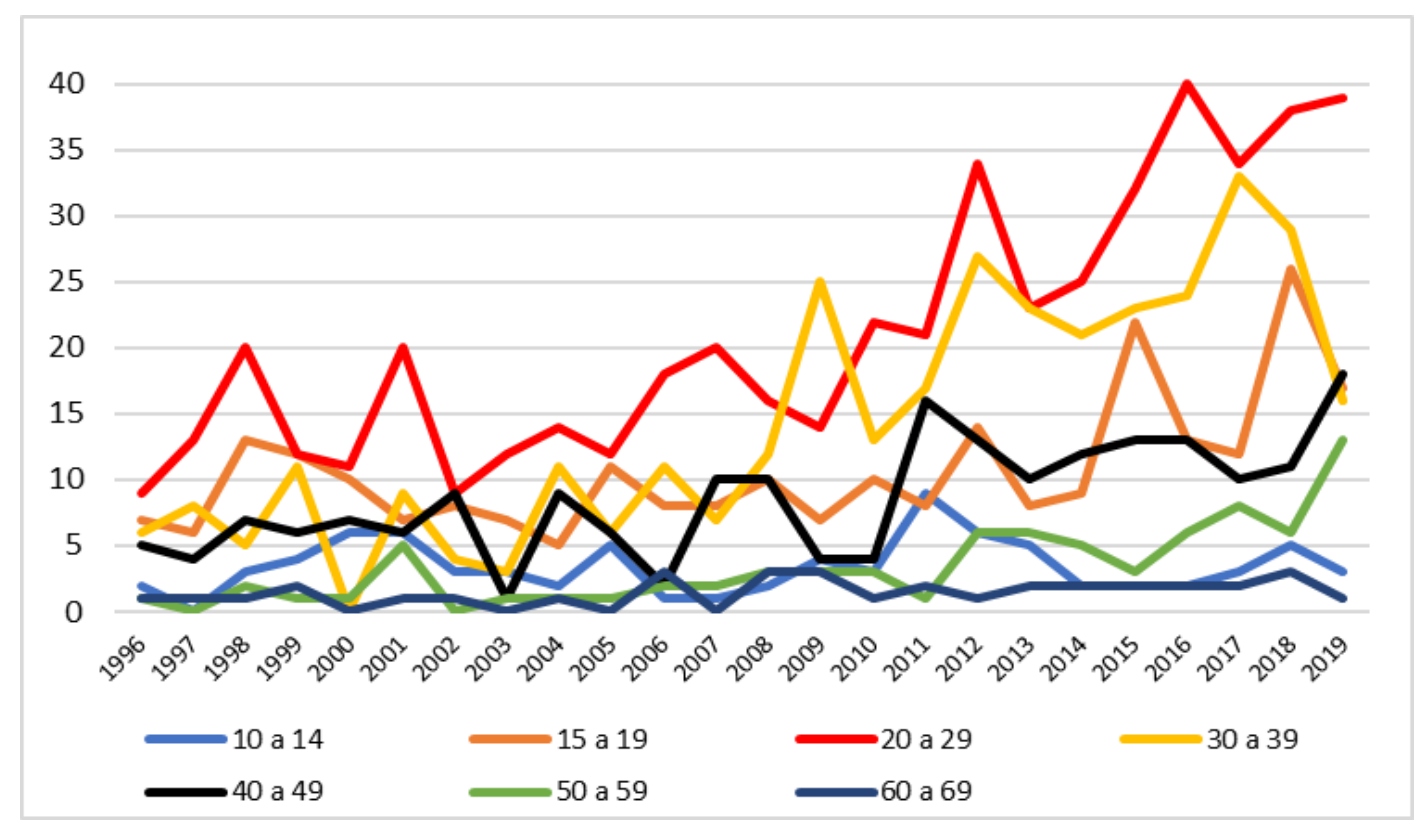

Fonte: MS/SVS/CGIAE - Sistema de Informações sobre Mortalidade - SIM

De forma parecida ao que ocorre com os homens, os grupos com maiores exposições à estas fatalidades são os de 20 a 29 e de 30 a 39 anos. As últimas posições são referentes às mulheres com 50 a 59 anos e de 60 a 69 anos. No meio destes eventos, transitam os dois grupos mais jovens, com redução percebida a partir de 2014 para as de 10 a 14 anos de idade.

Em Garcia et al (2008), verifica-se que as lesões mais comuns detectadas são as feridas contusas que atingem freqüentemente cabeça, pescoço e os membros superiores. Os casos de internação evidenciam a gravidade da violência, sendo que as especialidades da odontologia buco-maxilo-facial, ortopedia e traumatologia, e clínica médica são as que mais prestam atendimento. É necessário ressaltar a importância da sensibilização dos profissionais de saúde para o acompanhamento dessas mulheres e da notificação desses casos.

\subsection{Mortes por agressões físicas - por escolaridade}

Os dados de mortes de mulheres por escolaridade no estado do Amazonas, têm mostrado que as mulheres com maiores óbitos por agressão fazem parte do grupo daquelas com escolaridade de 4 a 7 anos de estudo, com o maior pico em 2017, ultrapassando 700 mortes. Compreende a cobertura de ensino fundamental incompleto.

A segunda posição é das mulheres com 8 a 11 anos de estudo. Estas fazem parte do grupo de ensino médio incompleto. Estes dois grupos representam os maiores volumes de mortes decorrentes das agressões, com tendencia de crescimento em toda a série histórica. O terceiro grupo é o de escolaridade de 1 a 3 anos de estudo, com picos em 2000 e 2012, oscilando entre o período estudado.

Por último, o grau de instrução com 12 anos e mais de estudo, mostra as menores quantidades de evento na série, evidenciando, no entanto, que mesmo entre estas mulheres mais estudadas, as agressões são uma realidade vivenciada. 
Figura 3: Mortes por agressão física de mulheres no Amazonas por escolaridade.

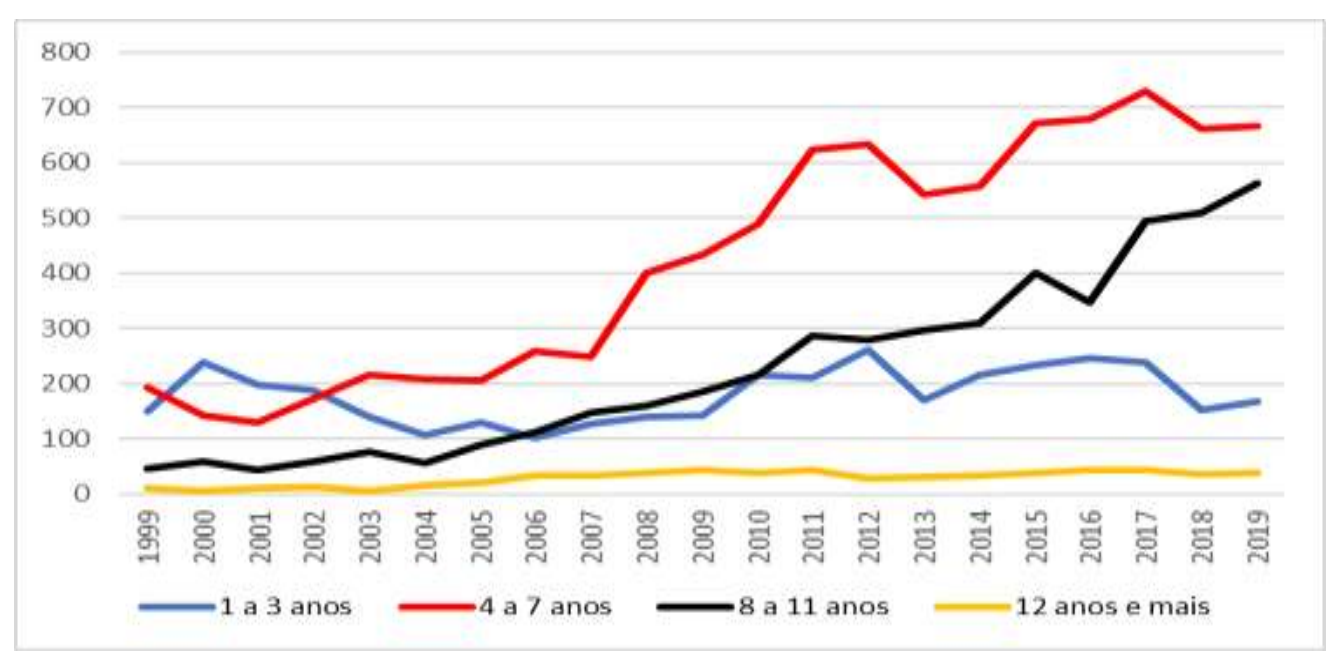

Fonte: MS/SVS/CGIAE - Sistema de Informações sobre Mortalidade - SIM

As agressões aparentam ter relação estreita com os homens. Assim destaca Souza (2005), apontando que os homens são as maiores vítimas da violência. Enfatiza-se que o gênero masculino ainda é fortemente configurado por práticas machistas e de risco e que essas práticas são as mesmas que constituem os homens como maiores vítimas da violência. No Brasil, essas questões são potencializadas pelas intensas desigualdades e outras condições adversas à cidadania.

Figura 4: Mortes por agressão de homens no Amazonas por escolaridade.

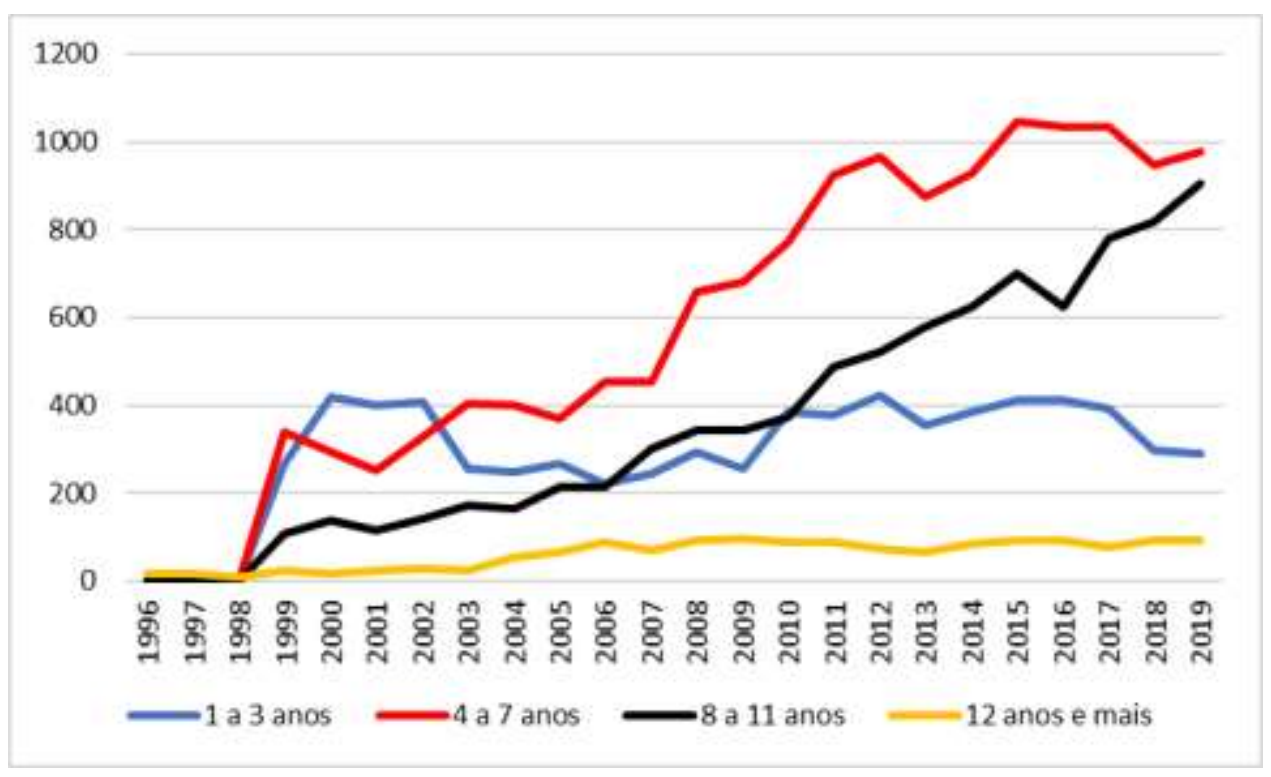

Fonte: MS/SVS/CGIAE - Sistema de Informações sobre Mortalidade - SIM

Assim, na Figura 4 nota-se que até o ano 2003, as mortes decorrentes de agressões físicas são maiores nos dois primeiros grupos (de 1 a 3 e de 4 a 7 anos de escolaridade). Isso se modifica a partir de 2004, com o progressivo crescimento das mortes da escolaridade de 4 a 7 anos até ao final da série histórica, apresentando oscilação no primeiro grupo. Grupo que se destaca também é o de 8 a 11 anos de estudo com elevação das mortes da questão estudada. A menor quantidade de fatalidades é percebida nos homens com mais de 12 anos de estudo, semelhante ao que se verifica na Figura 3. 


\subsection{Mortes por agressões físicas - estado civil}

O estado civil é um importante elemento no quesito de se perceber o contexto de vida de um indivíduo. Conforme Monteiro (2013), no contexto da dinâmica social, tal estado civil deve ser definido, juridicamente, adequando-se aos fenômenos que emergem na coletividade. Em relação a isso, exige-se plena identificação dos sujeitos que compõem esta relação convivencial, não somente para o aperfeiçoamento da compreensão de tal entidade familiar, mas também para garantir aos companheiros/conviventes a digna identificação na ordem jurídica, seja na teoria, seja na prática. As Figuras 5 e 6 apresentam as mortes resultantes de agressões físicas para as mulheres e homens no Amazonas por estado civil

Figura 5: Mortes por agressão física de mulheres no Amazonas por estado civil.

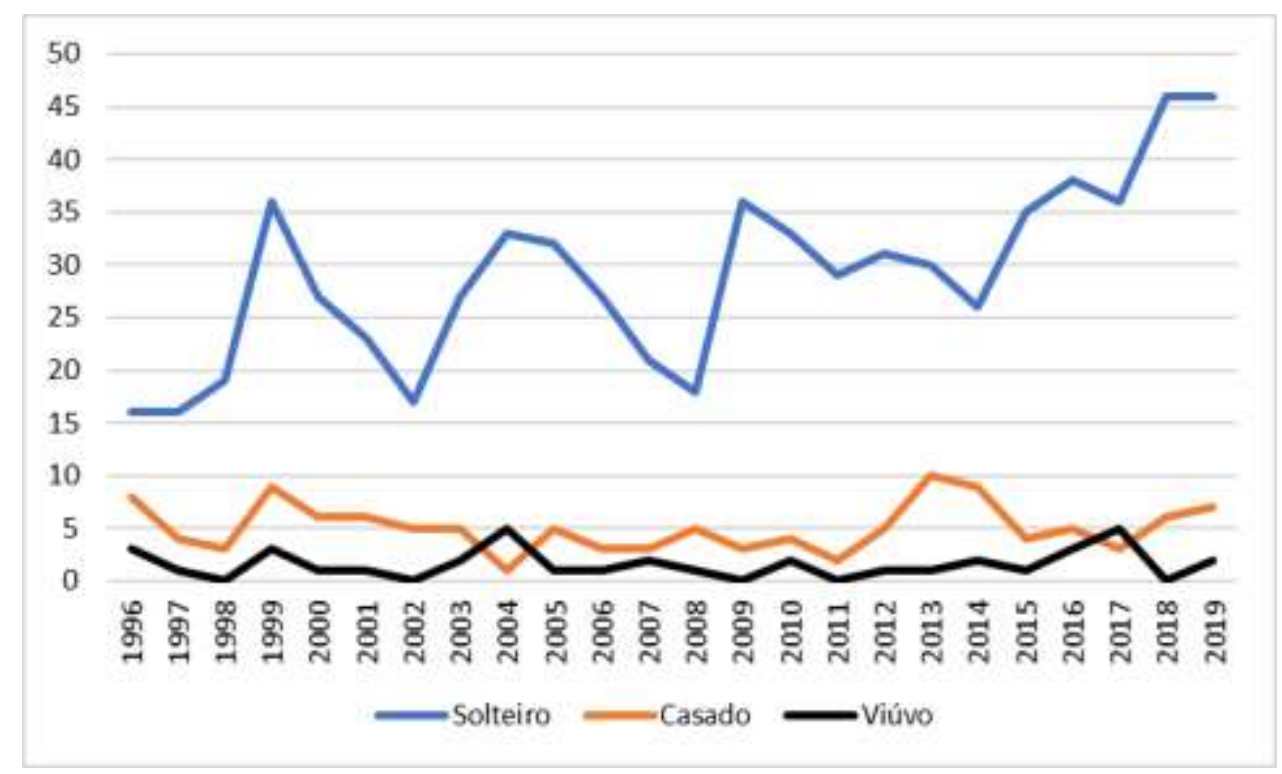

Fonte: MS/SVS/CGIAE - Sistema de Informações sobre Mortalidade - SIM

Por meio dos dados percebe-se que as mulheres solteiras são as que mais são afetadas pelas mortes resultantes de agressão nos 23 anos desta série histórica, apontando crescimento asustador, pois em 1996 eram pouco mais de 16 mulheres e em 2019, um número maior que 45 mulheres vítimas desta tipificação da violência.

Estudo realizado por Garcia et al (2008), mostra que a violência contra as mulheres atendidas nessas instituições atinge principalmente aquelas de 18 a 39 anos, amasiadas, de diferentes profissões, mas principalmente do lar e domésticas. É praticada principalmente pelos amásios e esposos, os quais apresentam perfil sócio-econômico e etário que se assemelha ao das vítimas. As agressões ocorrem dentro dos próprios lares, e segundo as vítimas, motivadas pelos vícios e o ciúme; a esperança de que o relacionamento conjugal melhore faz com que as mulheres permaneçam na relação violenta.

Em escalas menores encontram-se as mulheres que são casadas e as viúvas. Nestes dois grupos, nota-se também traços de elevada violência, pois do início ao final da série histórica, há um movimento de picos e vales se alternando, sendo mais altos nos períodos 2013, 2014 e 2019. As viúvas, de igual modo são potenciais vítimas deste contexto, com participação mais suavizada, conforme mostram os dados. Os maiores eventos ocorreram nos anos 1996, 1996, 2004 e 2017.

Conforme Maders e Angelin (2014), a Lei no 11.340/2006 (Lei Maria da Penha) causou um impacto positivo por ter trazido a violência ao debate e por seu caráter pedagógico ao punir os agressores mais severamente, o que contribui para reduzir a violência contra as mulheres sem, contudo, acabar com ela. Isso exige o reforço de algumas medidas, a tomada de outras e o desenvolvimento de novos projetos. De forma semelhante ao que se percebe na abordagem para as mulheres, os 
homens viúvos e os casados são os que são acometidos com os menores eventos de mortes por agressão na série histórica observada.

Na Figura 6 as observações recaem sobre os homens e o nível de mortes decorrentes de agressão por uma ótica da escolaridade. Faz-se uso dos dados da mesma forma disposta para a abordagem anterior. Os homens solteiros de igual modo ao que ocorre com as mulheres, são os que apresentam a maior participação de mortes por agressão.

Figura 6: Mortes por agressão física de homens no Amazonas por estado civil.

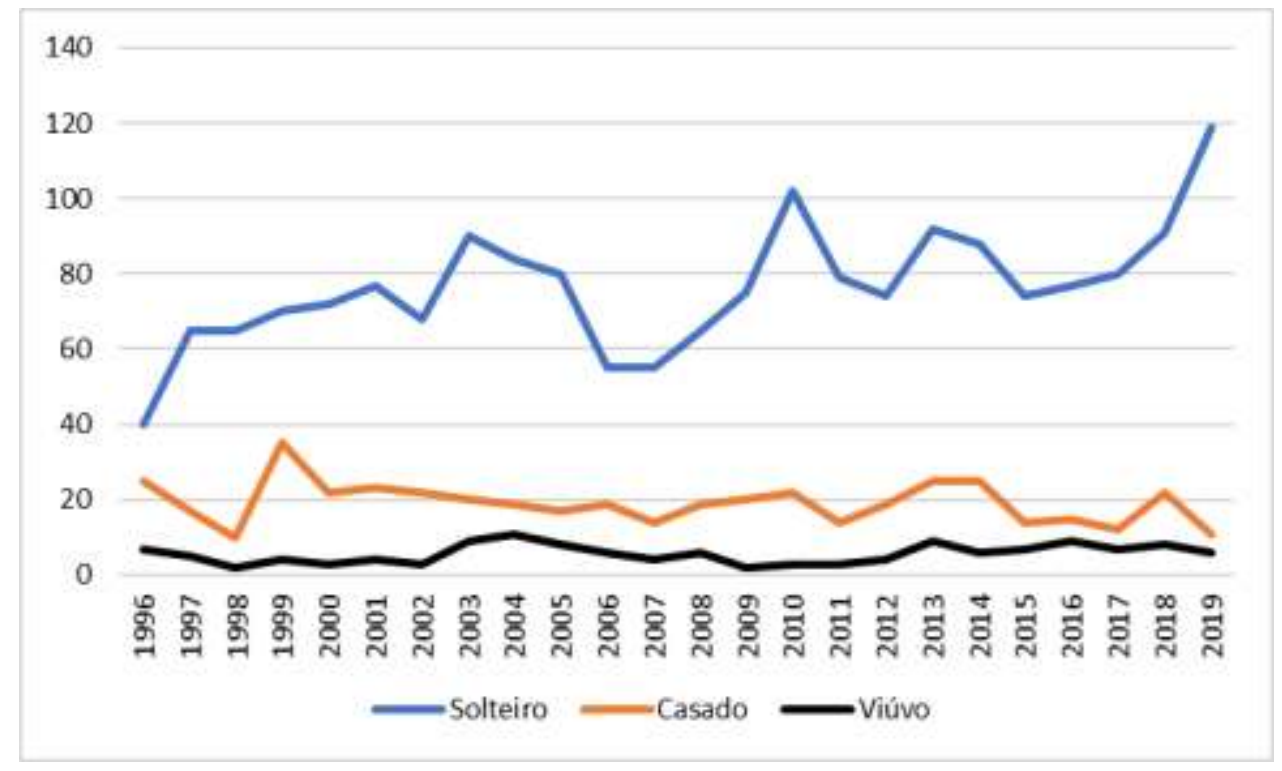

Fonte: MS/SVS/CGIAE - Sistema de Informações sobre Mortalidade - SIM

Assusta a forma que se apresenta o crescimento destas ocorrências. No início da série histórica, a quantidade de mortes era o equivalente a 40 nos homens solteiros e nos 23 anos que seguem a abordagem percebe-se manutenção deste comportamento, com ligeira redução nos anos de 2005 a 2009, retomando crescimento até o final da série em 2019 com o equivalente a 120 mortes neste ano para o estado do Amazonas. De forma semelhante ao que se percebe na abordagem para as mulheres, os homens viúvos e os casados são os que são acometidos com os menores eventos de mortes por agressão na série histórica observada.

\subsection{Mortes por agressões físicas - considerando o local de ocorrência}

Esta seção apresenta a trajetória das mortes decorrentes de agressões, por local de ocorrência. Neste quesito se verifica aquelas ocorridas em hospitais, nos domicílios e nas vias públicas. O hospital é o local onde se busca o socorro imediato, pois nestas circunstâncias a saúde ou as possibilidades de manutenção de vida podem ser obtidos. No caso das agressões nota-se que este é o local onde a maior quantidade de óbitos se dá em toda a série histórica, intercalando-se com aquelas ocorridas em via pública. Detalhe significativo é o de que estas últimas são maiores no final da série histórica.

A morte em via pública é uma das situações onde algumas questões pesam, pois a fatalidade é tão iminente que não há se quer condições de que a vítima seja socorrida ou chegue a uma estrutura que atue no sentido de impedir a morte. Nesta tipologia de episódio, inclui-se a adversidade acometida à juíza Viviane Vieira do Amaral Arronenzi, do Tribunal de Justiça do Rio de Janeiro, foi morta na noite de Natal (24/12/2020) a facadas pelo ex-marido, que foi detido e preso em flagrante1.

\footnotetext{
${ }^{1}$ https://www.conjur.com.br/2020-dez-25/juiza-tj-rj-assassinada-ex-marido-noite-natal
} 
Um local comum relacionadao à violência contra a mulher, são as agressões na residência da própria vítima. Isso corrobora com o dado encontrado que a maioria dos agressores tem algum tipo de relação com a vítima, tendo acesso a sua residência e realizando as agressões dentro do seu próprio lar. Esse dado é extremamente preocupante, pois as vítimas de agressão não tem sequer seu lar como ambiente seguro, trazendo, também, conflitos psicológicos à vítima, (Oliveira et al 2019). Nas Figuras 7 e 8 mostra-se as mortes decorrentes de agressões físicas para mulheres e homens no Amazonas, considerando o local onde se efetivou o óbito.

Figura 7: Mortes por agressão física de mulheres no Amazonas por local de ocorrência.

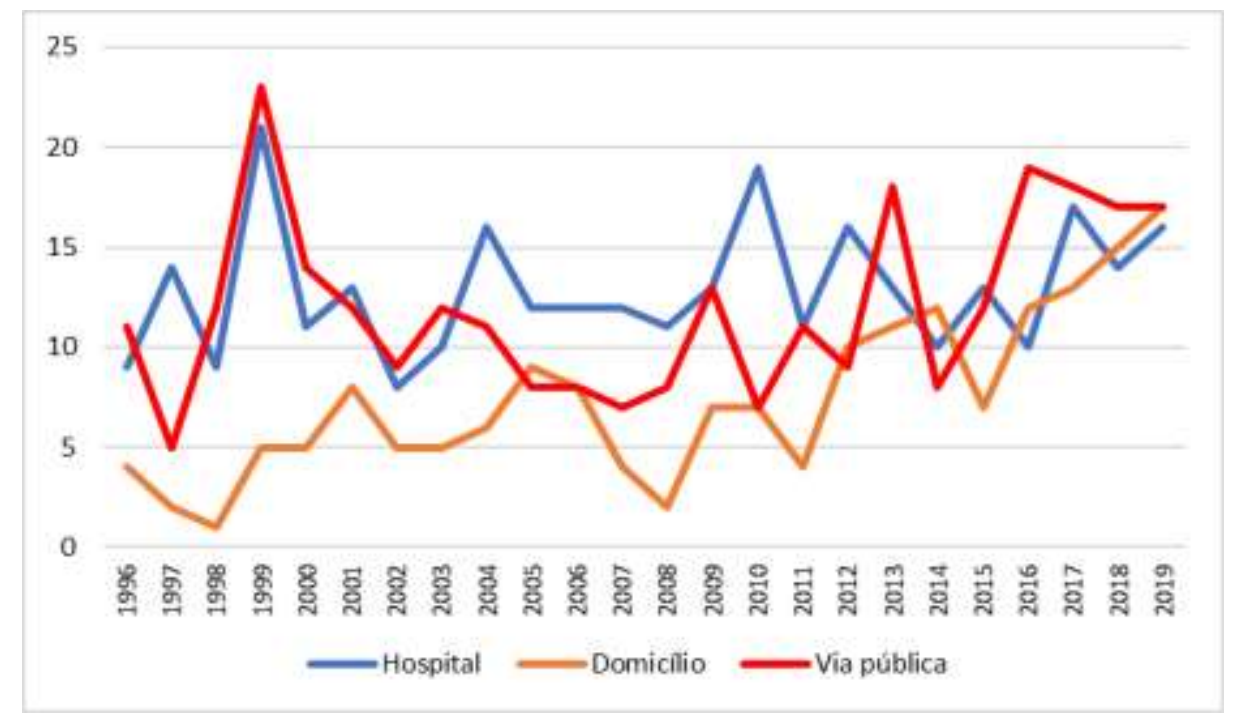

Fonte: MS/SVS/CGIAE - Sistema de Informações sobre Mortalidade - SIM

As mortes por agressão para os homens, mostram-se em quantidade dobradas no período observado. A figura 8, de igual modo, deixa claro que o hospital é o local onde ocorrem a maioria das mortes decorrentes deste tipo de violencia, em todo o período da série histórica. Os domicílios e as vias públicas são os locais onde significativa quantidade de pessoas são perdidas para a violência.

Figura 8: Mortes por agressão física de homens no Amazonas por local de ocorrência.

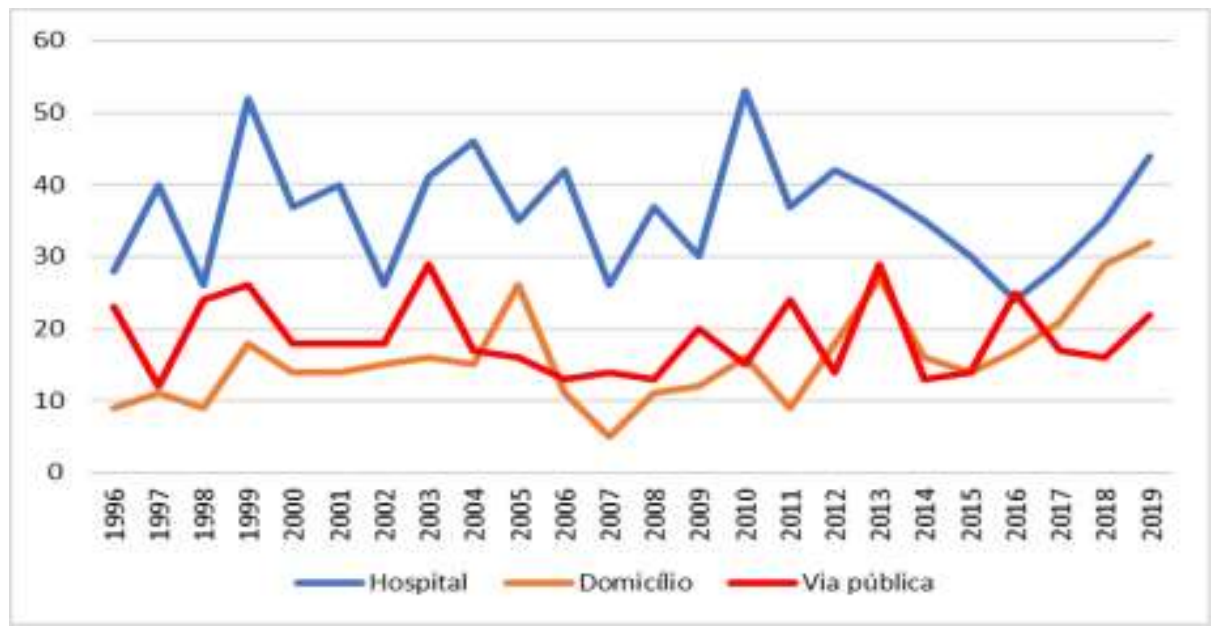

Fonte: MS/SVS/CGIAE - Sistema de Informações sobre Mortalidade - SIM 
Observar o que ocorre com os homens que morrem em decorrência das agressões, reforça o que se percebe em Souza (2005), quando afirma que embora esse modelo hegemônico de masculinidade construído a partir de valores patriarcais e machistas já tenha sido tão amplamente criticado e mesmo que em época recente ele conviva com outros modelos, ainda prepondera a noção de que existe associação entre essa masculinidade viril, competição e violência, conforme Souza (2005).

\section{Conclusão}

A violência é percebida diariamente. Seus efeitos em formas de agressão, tanto em figura de agredido ou agressor é algo que impacta em função das suas consequências, que por vezes são fatais. Buscou-se apresentar neste trabalho, peculiaridades relacionadas às mortes que ocorreram em decorrência de agressões numa linha de tempo de 23 anos, começando em 1996 estendendo-se a 2019, para o estado do Amazonas. Fez-se isso envolvendo homens e mulheres, considerando a faixa etária, a escolaridade, o estado civil e o local onde se deu o evento fatídico.

Os resultados sinalizam que se perde uma juventude significativa no quesito mortes por agressão. Dos sete grupos estudados, tanto para homens quanto para mulheres, três destes são os que se destacam com os maiores eventos: 15 a 19; 20 a 29 e 30 a 39 anos. Mostraram ainda, que à medida que a escolaridade se eleva, as mortes decorrentes de agressão são menores apontando que a instrução (seja ela no nível que for) pode ser um coadjuvante que axuilie na redução das perdas.

Considerando-se o estado civil, os resultados mostraram que os solteiros e as solteiras são os mais afetados por esse tipo de mortes, deixando claro no entanto, que até entre os casados, não é garantida a isenção nestas fatalidades. Fato que reforça o uso efetivo da Lei Maria da Penha (Lei ${ }^{\circ}$ 11.340/2006) como uma das maiores conquistas legislativas que surgiu nesta seara, fortalecendo e tentando garantir a vida dos agredidos. A violência doméstica, é um sério problema social que afeta milhares de mulheres cotidianamente em todo o mundo em todas as idades, classes sociais, etnias, graus de escolaridade, orientação sexual e religião, é considerada uma das mais graves manifestações de violência de gênero, (Côrtes, 2008).

O local das mortes aponta que boa parte destas se dá em vias públicas e em hospitais para as mulheres, com relativa representatividade de óbitos em domicílio. Para os homens, a maioria absoluta se manifesta em hospital, com eventos muito próximos em via pública e nos domicílios, porém em escalas menores. Assim, a violência ainda é uma das mazelas mais graves que acompanham humanidade, mas que carece de ações de enfrentamento e tratativa.

Para trabalhos futuros pretende-se dar continuida à temática abordada, estendo-se para as demais Unidades de Federação (UF’s) do Brasil, na tentativa de se perceber o comportamento tido nestas esferas, pontuando quais são as estratégias de ação e interação entre o Estado e as Instituições que labutam nesta seara tão carente de operacionalização estratégica na preservação daquilo de mais precioso que se tem: a vida.

\section{Referências}

Barros, P., \& Silva, F. B. N. (2006). Origem e manutenção do comportamento agressivo na infância e adolescência. Revista Brasileira de Terapias Cognitivas, 2(1), 55-66.

Bonamigo, I. S. (2008). Violências e contemporaneidade. Revista Katálysis, 11 (2), 204-213.

Côrtes, G. R. (2008). Violência Doméstica contra Mulheres - Centro de Referência da Mulher - Araraquara. Tese de doutorado Programa de Pós-Graduação em Sociologia, da Faculdade de Ciências e Letras. São Paulo.

Dias, E. O. (2000). Winnicott: agressividade e teoria do amadurecimento. Natureza humana, 2(1), 9-48.

Garcia, M. V., Ribeiro, L. A., Jorge, M. T., Pereira, G. R. \& Resende, A. P. (2008). Caracterização dos casos de violência contra a mulher atendidos em três serviços na cidade de Uberlândia, Minas Gerais, Brasil. Cadernos de Saúde Pública, 24(11), 2551-2563.

Günther, Hartmut. (2006). Pesquisa qualitativa versus pesquisa quantitativa: esta é a questão? Psicologia: Teoria e Pesquisa, 22 (2), 201209. 
Research, Society and Development, v. 10, n. 2, e44310212782, 2021

(CC BY 4.0) | ISSN 2525-3409 | DOI: htttp://dx.doi.org/10.33448/rsd-v10i2.12782

Maders, A. M., \& Angelin, R. (2014). Direitos humanos e violência doméstica contra as mulheres: oito anos de encontros e desencontros no Brasil. Faces de Eva. Estudos sobre a Mulher, (32), 41-58.

Mezzaroba, O.; Monteiro, C. S. (2009). Manual de metodologia da pesquisa no direito. Saraiva. 344 p.

Minayo, M. C. S. (2006). Violência e saúde. Rio de Janeiro: Editora FIOCRUZ, 2006. Temas em Saúde collection. 132 p.

Misse, M. (2019). Alguns aspectos analíticos nas pesquisas da violência na América Latina. Estudos Avançados, 33 (96), 23 -38.

Monteiro, E. J. F. (2013). O reconhecimento da união estável como estado civil. - Trabalho de Conclusão de Curso (Bacharelado em Ciências Jurídicas e Sociais - Direito). Centro de Ciências Jurídicas e Sociais, Universidade Federal de Campina Grande - Sousa- Paraíba Brasil.74 fl.

Moura, M. A. V., Netto, L. A., \& Souza, M. H. N. (2012). Perfil sociodemográfico de mulheres em situação de violência assistidas nas delegacias especializadas. Escola Anna Nery, 16(3), 435-442.

Naves, Maria Margareth Veloso. (1998). Introdução à pesquisa e informação científica aplicada à nutrição. Revista de Nutrição, 11(1), 1536.

Oliveira, M. V. J., Lima, M. R. P., Silveira, G. M., Correia, A. M., Almeira, M. E. L., Teixeira, A. K. M. (2019). Análise temporal das agressões físicas contra a mulher sob a perspectiva da odontologia legal na cidade de Fortaleza, Ceará. Revista Brasileira de Odontologia RBOL.

Sá, A. A. (1999). Algumas questões polêmicas relativas à psicologia da violência. Psicologia: Teoria e Prática. 1(2): 53-63

Souza, E. R. (2005). Masculinidade e violência no Brasil: contribuições para a reflexão no campo da saúde. Ciência \& Saúde Coletiva, 10(1), 59-70. 